\title{
Las organizaciones culturales y su relación con las redes sociales virtuales. Caso: Arena y Esteras
}

\author{
Cultural organizations and their relationship with virtual social networks. \\ Case: Arena and Mats
}

\section{Organizações culturais e sua relação com as redes sociais virtuais. Caixa: Areia e Esteiras}

\section{Walter Vladimir Saldaña Manche}

Universidad Nacional Mayor de San Marcos (Perú)

Waltersaldana79@gmail.com

Código ORCID: https://orcid.org/0000-0003-2965-1328

\begin{abstract}
RESUMEN
El presente trabajo de investigación tiene como eje principal conocer a la Asociación Cultural Arena y Esteras además de cómo han ido evolucionado en el tiempo. Asimismo, se busca descubrir la influencia que tienen las redes sociales virtuales especialmente la cuenta de Facebook, en el crecimiento de su institución. Para poder entender este caso se ha hecho una exploración a los principales conceptos de organización, cultura organizacional, redes sociales virtuales e internet. Posteriormente se procede a revisar los acontecimientos que marcaron el inicio de la organización, las diversas dificultades que tuvieron que superar y los reconocimientos que obtuvieron por su trabajo en favor de comunidad. Luego se efectúa una investigación sobre los principales conceptos de redes sociales virtuales e internet, además, se hace un análisis de los mensajes que se publican, especialmente en la cuenta de Facebook de Arena y Esteras. Finalmente, se presentan de manera ordenada y detallada las conclusiones donde se menciona las diversas mejoras que deberían realizar tanto a nivel organizacional, como a nivel comunicacional.
\end{abstract}

\begin{abstract}
The present research work has as main axis to know the Cultural Association Arena and Mats and how they have evolved over time. It also seeks to discover the influence that virtual social networks have, especially the Facebook account, in the growth of its institution. In order to understand this case, an exploration has been made of the main concepts of organization, organizational culture, virtual social networks and the Internet. Subsequently, we proceed to review the events that marked the beginning of the organization, the various difficulties they had to overcome and the recognition they obtained for their work in favor of community. Then an investigation is carried out on the main concepts of virtual social networks and the Internet, in addition, an analysis is made of the messages that are published, especially in the Facebook account of Arena and Esteras. Finally, the conclusions are presented in an orderly and detailed manner, mentioning the various improvements that should be made both at the organizational level and at the communication level.
\end{abstract}

\section{RESUMO}

O eixo principal deste trabalho de pesquisa é conhecer a Associação Cultural Arena y Esteras e como ela evoluiu ao longo do tempo. Da mesma forma, busca descobrir a influência das redes sociais virtuais, especialmente a conta do Facebook, no crescimento de sua instituição. Para a compreensão

Saldaña, M. (2020). Las organizaciones culturales y su relación con las redes sociales virtuales. Caso: Arena y Esteras. Espiral, revista de geografías y ciencias sociales, 2(3), 057 - 068. http://dx.doi.org/10.15381/espiral.v2i3.18449 
deste caso, foi feita uma exploração dos principais conceitos de organização, cultura organizacional, redes sociais virtuais e internet. Posteriormente, procedemos a uma revisão dos acontecimentos que marcaram o início da organização, as várias dificuldades que tiveram de superar e os reconhecimentos que obtiveram pelo seu trabalho a favor da comunidade. Além disso, é feita uma análise das mensagens publicadas, principalmente na conta do Facebook da Arena y Esteras. Por fim, as conclusões são apresentadas de forma ordenada e detalhada, referindo as várias melhorias que devem ser feitas tanto ao nível organizacional como ao nível da comunicação.

PALABRAS CLAVES: Organización; Cultura Organizacional; Internet; Arena y Esteras; Facebook.

KEYWORDS: Organization; Organizational Culture; Internet; Sand and Mats; Facebook.

PALAVRAS CHAVES: Organização; Cultura Organizacional; Internet; Arena y Esteras; Facebook.

\section{INTRODUCCIÓN}

Era la mañana del 15 de febrero de 1992, cuando de repente se escuchan gritos de desesperación, habían asesinado a una joven dirigente sindical llamada María Elena Moyano, este crimen cambio por completa a los ciudadanos de Villa El Salvador, su delito tener la firmeza de oponerse al paro organizado por el grupo terrorista Sendero Luminoso, pero no conformes con asesinarla la descuartizaron con la finalidad de atemorizar a todos los pobladores. La violencia del crimen generó que un grupo de jóvenes, un 29 de Marzo de 1992, tomaran la decisión más arriesgada de su vida, salir a las calles con una nariz roja, un par de zancos, un tambor y con un cartel que decía : ¡ Por el derecho a la sonrisa i.

Luego de las primeras actividades decidieron darle un nombre al grupo y a ninguno de sus integrantes se le ocurría hasta que surge Arena y Esteras, palabra que simbolizaba los inicios de Villa El Salvador, estos jóvenes cambiaron por completo el panorama de tristeza que había quedado tras el asesinato, desde ese instante se propusieron como objetivo ser una fuente de alegría. Han pasado por diversas situaciones a lo largo de todo este tiempo, pero en los últimos años han empezado a utilizar las redes sociales virtuales, especialmente la cuenta de Facebook, como una herramienta digital sumamente útil para la difusión de los talleres, las obras de teatro y los festivales de circo.

La organización cultural es un ejemplo por múltiples razones, una de ellas es que a pesar de la juventud de sus integrantes, tomaron la decisión de enfrentar a Sendero Luminoso con el firme propósito de realizar festivales teatrales alrededor de su comunidad para incentivar que los niños regresan a las clases en los colegios, a pesar del miedo de la población.

El objetivo principal del presente trabajo es conocer cómo nace la asociación, su historia, pero sobre todo descubrir de qué manera utilizan las redes sociales virtuales, especialmente la cuenta de Facebook, para divulgar los festivales de circo, obras de teatro y talleres que realizan a lo largo de todo el año.

\section{Historia de la organización cultural Arenas y Esteras}

El gran proceso migratorio de los peruanos que vivían en el campo y que luego se trasladaron a las zonas urbanas de la costa cambio por completo la estructura social de una capital en pleno proceso de urbanización. Esta gran población fue solicitando una vivienda donde instalarse para construir un futuro diferente, al no ser atendidas sus demandas, empiezan las primeras invasiones en los zonas más alejadas de Lima dando inicio a los primeros distritos en los grandes conos de la ciudad de los reyes.

Para investigadores como Portocarrero, F.; Sanborn, C.; Cueva, H. y Millán, A. (2002) en su libro Más allá del individualismo: el tercer sector en el Perú afirman que este 
proceso no tan solo significo un cambio "en la fisonomía social de las ciudades, sino también un cambio profundo en los propios migrantes, esto es, su ingreso en los complicados caminos de la modernidad urbana y multiétnica, de su cholificación" (p. 115).

De esta forma es como empieza aparecer una población obrera que todos los días se traslada de la periferia a los distritos donde se encontraba las fábricas, dando inicio a una nueva clase social que trae consigo las costumbres ancestrales del campo como la minga, que significa el trabajo colectivo con el objetivo de ayudar a la comunidad, dando inicio a las primeras obras de luz, agua, desagüe y de locales comunales.

Para investigadores como Panfichi y Alvarado (2009) en su trabajo Desconfianza y Control: Ong y Politica en el Perú, señala que la aparición de nuevos líderes barriales, los cuales dieron el punto de partida a nuevos partidos políticos, significó el camino para empezar "a desafiar las bases sociales, políticas y económicas del poder de la oligarquía, demandando la realización de reformas democratizadoras" (p.7).

En medio de ese escenario a mediados de los años sesenta, aparecieron las organizaciones no gubernamentales, las cuales brindaron ayuda sumamente importante, ya que ofrecieron asistencia técnica y legal para la formación de las primeras asociaciones de viviendas, así como apoyo social a los sectores económicos más desvalidos, ya que ninguna institución fue capaz de satisfacer la demanda de los nuevos limeños.

Para investigadores como Portocarrero et al. (2002) afirman que: "la razón de ser de las organizaciones privadas sin fines lucro es la provisión de bienes y servicios públicos y cuasi públicos cuando tanto el mercado como el estado han fracasado previamente en suministrarlos" (p. 22).

De acuerdo a la investigación de Panfichi y Alvarado (2009) las primeas dos organizaciones que se crearon en la Lima fueron el Instituto de Estudios Peruanos (IEP) en 1964 y el Centro de Estudios y Promoción del Desarrollo (DESCO) en 1965 que comenzaron a dar prioridad sobre puntos esenciales como la investigación académica y la promoción del desarrollo económico de la comunidad.

Estas ONG se caracterizaron por estar formadas, principalmente, por profesionales de izquierda de clase media y católicos progresistas, varios de ellos formados en colegios y universidades de influencia jesuita. La primera se especializa en la investigación académica de alto nivel concitando el apoyo de universidades sobre todo americanas e inglesas y fundaciones privadas como la Fundación Ford. La segunda por otro lado, estuvo desde un inicio más orientada a la promoción del desarrollo, con fuentes de apoyo económico europeo y vinculado directo o indirectamente a la Iglesia Católica (Panfichi y Alvarado, 2009 p. 7).

Para esta investigación realizó un análisis de la asociación artística y cultural Arena y Esteras, ubicada en la ciudad de Lima, en el distrito de Villa El Salvador. Esta organización es una referente para toda su comunidad, ya que a lo largo de estos 27 años de funcionamiento, se ha convertido en una fuente de cultura y entretenimiento.

El surgimiento de esta asociación empezó en un momento sumamente complicado en la capital, ya que el grupo terrorista Sendero Luminoso estaba avanzando con sus crímenes en la ciudad. De acuerdo al sociólogo Nelson Manrique (2015) los atentados ocurridos correspondían a un plan que tenía varias fases siendo la primera: "la oleada violentista programada para cerrar la segunda campaña de su V plan se realizó en febrero de 1992 e incluyó múltiples atentados en la capital, así como el asesinato de varios dirigentes populares entre ellos la heroica María Elena Moyano". (Manrique, 2015, p. 227) 
El asesinato de María Elena Moyano cambio por completo a toda Villa El Salvador, varios de sus dirigentes estaban aterrorizados, dejando de participar en las actividades comunales y muchos pobladores decidieron quedarse callados. Por otro lado, tenían un dolor muy grande, ya que era la presidente de la Federación Popular de Mujeres de Villa El Salvador, "implicaba la muerte política del grupo terrorista, pues las mayorías populares reaccionaron alzándose contra un hecho que no tenía alegato: asesinar a una persona tan querida por el pueblo era ir contra este, no su opuesto, como pretendía ser el discurso del PCP-SL" (Arena y Esteras, 2016, web).

Arturo Mejia (comunicación personal, 2 enero, 2018), fundador de la organización, relata que las personas vivían atemorizadas, encerradas en sus casas y no dejaban que sus hijos vayan a la escuela por temor de ser asesinados. Por tal motivo, Arturo, Sofía y otros participantes decidieron juntarse con la finalidad de llevar un mensaje de alegría y de esta forma impulsar a que los niños regresen a las escuelas. De acuerdo al documento ¡Por derecho la Sonrisa! de autoría de Arena y Esteras (2016) señala que:

Recorríamos las calles para convocar la confianza que nos había arrebatado la violencia. Jugar con los niños en cada parque central, hacer títeres con papel usado o pintar con crayolas los miedos y sueños, fueron los primeros pasos de una ruta en la que no nos sentíamos artistas, sino dirigentes con un nuevo modo de llegar a la población. Idear nuevos discursos desde lo lúdico, lo creativo y colorido, fue la piedra angular que cimentó el nacimiento de Arena y Esteras (p.21).

De esta manera es como nace Arena y Esteras, un 29 de marzo de 1992, en las primeras reuniones de sus fundadores solo se establecía a que unidad vecinal harían el pasacalle, sin considerar los riesgos que se exponían si ocurría un atentado terrorista. Por otro lado, los ciudadanos los recibían con alegría, ya que los payasos y los zancos arrancaban una sonrisa a las personas.

Para Arturo Mejía, esta forma de presentarse ante la comunidad, era una forma de demostrar que la vida continua que a pesar de todos los problemas es importante mirar la vida con optimismo, asimismo era una estrategia educativa que buscaba rescatar los valores de unidad y esfuerzo para salir adelante.

Realizar una representación teatral permite a las personas primero potenciar su capacidad de aprendizaje y segundo mejorar su vocalización y desenvolvimiento frente a desconocidos. Además despierta su creatividad para superar obstáculos. Asimismo, sirve para elevar su autoestima, ayuda a mejorar su nivel de socialización, así como disminuye su timidez y su inseguridad.

Arena y Esteras tenía como premisa esencial que la población toma conciencia de problemáticas sociales como defensa del medio ambiente, cuidar su comunidad, defensa de los derechos humanos, conocer, respetar y sentirse orgullosos de su interculturalidad, además de realizar manifestaciones a favor de la cultura de paz en rechazo al terrorismo. Como bien señala Arturo Mejía (comunicación personal, 2 enero, 2018) donde manifiesta lo siguiente:

Nuestro compromiso era de llevar a alegría a los niños, era lo que nos tocaba hacer en este momento. Luchar por lo que es nuestro a pesar de los militares o los senderistas. Algunas dirigentes vecinales nos apoyaban y otros nos decían que no realicemos ninguna actividad, que era peligroso, pero la nariz roja tiene su propio lenguaje. (Mejia, 2018).

Después de los dos primero años de realizar presentaciones, empiezan a recibir diversos premios por su trabajo. Recién en el año 1994, comienza una nueva etapa, ya que deciden participar en la muestra nacional de teatro, donde reciben un reconocimiento por la presentación que realizan. Este acontecimiento generó la consolidación del grupo, dando inicio a una temporada de presentaciones a lo largo de varias ciudades del país. 
En el año 1995, Arena y Esteras ganó un crédito que permitía financiar un negocio, de esta manera es que surge la iniciativa de un bazar denominado Arlequín, donde se ofrecían diversos servicios. A los dos años siguientes cierran la tienda, ya que los estaba absorbiendo demasiado. Luego ganan un contrato, con el Ministerio de Salud, donde se comprometían a pintar de 300 murales, en las diversas postas médicas de todo Lima. A raíz de la ganancia generada por realizar este trabajo es que deciden comprar un lote de terreno y luego construir una casa cultural comunitaria llamada Arena y Esteras.

Una vez concluida la construcción deciden dictar talleres para los niños, adolescentes y jóvenes. A partir del año 1999 vuelven a poner en escena la obra llamada Arenas de Villa, creado por ellos mismos y que cuenta la historia de Villa El Salvador. La obra cuenta el surgimiento de las primeras comunidades y asimismo muestra como a través del trabajo solidario de sus pobladores se logró alcanzar las metas que se propusieron. De esta forma es como empieza a crecer su elenco y deciden participar en la siguiente muestra nacional de teatro, donde nuevamente reciben un premio por su trabajo.

En el año 2000 ocurren un cambio, los directores deciden por primera vez realizar un trabajo en conjuntos con otras cuatro organizaciones, llamado "Chibolos Unidos", el cual consistía en convocar a los alumnos de las escuelas para usar su tiempo libre en actividades como teatro, circo, danza, música, zancos, etc.

A partir del año 2007 se empieza a realizar obras de creación colectiva algunos de los títulos son: la carreta de los sueños, arenas de villa, entre otros. Además se hicieron coproducciones con grupos de teatro del extranjero, muchos se quedaban hospedados en la casa cultural y luego dictaban talleres para los adolescentes y jóvenes.

Desde el año 2010 hacia de adelante se han convertido en una de las principales organizaciones promotora del arte. Asimismo, han participado en diversos concursos a nivel nacional e internacional, donde han recibido una serie de reconocimientos. Pero su ingresó al ciberespacio recién es a partir del año 2008 con un blog, para este utilizaron la plataforma virtual Blogspot.com. Esta página web funcionaba como un diario de la institución donde mostraban sus principales actividades acompañadas de fotografías.

Sin embargo, se dieron cuenta que necesitaban involucrarse más en el ciberespacio, es así como deciden incursionar en una de las redes sociales virtuales que estaba en mayor crecimiento como Facebook, 28 de abril de 2010, crean una cuenta en donde colocan el logo principal de la asociación y empiezan a publicar sus primeras notas acompañadas de sus respectivas imágenes.

En el año 2012 el Ministerio de Cultura le entrego a la asociación Arena y Esteras el premio nacional de cultura en la categoría "Buenas Prácticas Culturales". Arturo Mejía mencionó que el premio es fruto del trabajo colectivo de todos sus integrantes, además señaló que mostrar la cultura de un pueblo es destacar los valores de la sociedad y despertar en los individuos una responsabilidad de ayudar a tu prójimo para alcanzar el bienestar social.

\section{Las redes sociales y su influencia en las organizaciones culturales.}

En los últimos años las redes sociales virtuales han tenido un crecimiento exponencial de usuarios, de acuerdo a las estadísticas de Ipsos Perú, en el año 2016 eran alrededor de 10, 280, 920 a nivel nacional; mientras que dos años después, en el año 2018 son alrededor de 11, 2 millones personas que participan de manera activa.

Otra de las conclusiones que se puede obtener es que la red social virtual Facebook se encuentra primera con un $98 \%$, luego sigue Whatssap con un $72 \%$, Youtube con un 33 
$\%$, Instagram con un $24 \%$, Google+ con un $18 \%$ y Twitter con un $10 \%$. Esto demuestra el nivel de influencia que tienen en los ciudadanos y como son determinantes en distintos aspectos de la vida cotidiana.

En el caso de las organizaciones también se han visto afectadas, ya que actualmente para tener un mayor impacto en sus clientes o colaboradores de manera efectiva y rápida utilizan las redes sociales virtuales, inclusive para investigadores como Fernández y Alfaro (2017) cuando una "organización se anima a utilizar este medio desde una perspectiva profesional, en el que el community manager plantea una estrategia alineada a los objetivos del negocio, se estaría descantando la comunicación improvisada, puramente informal" (p.29).

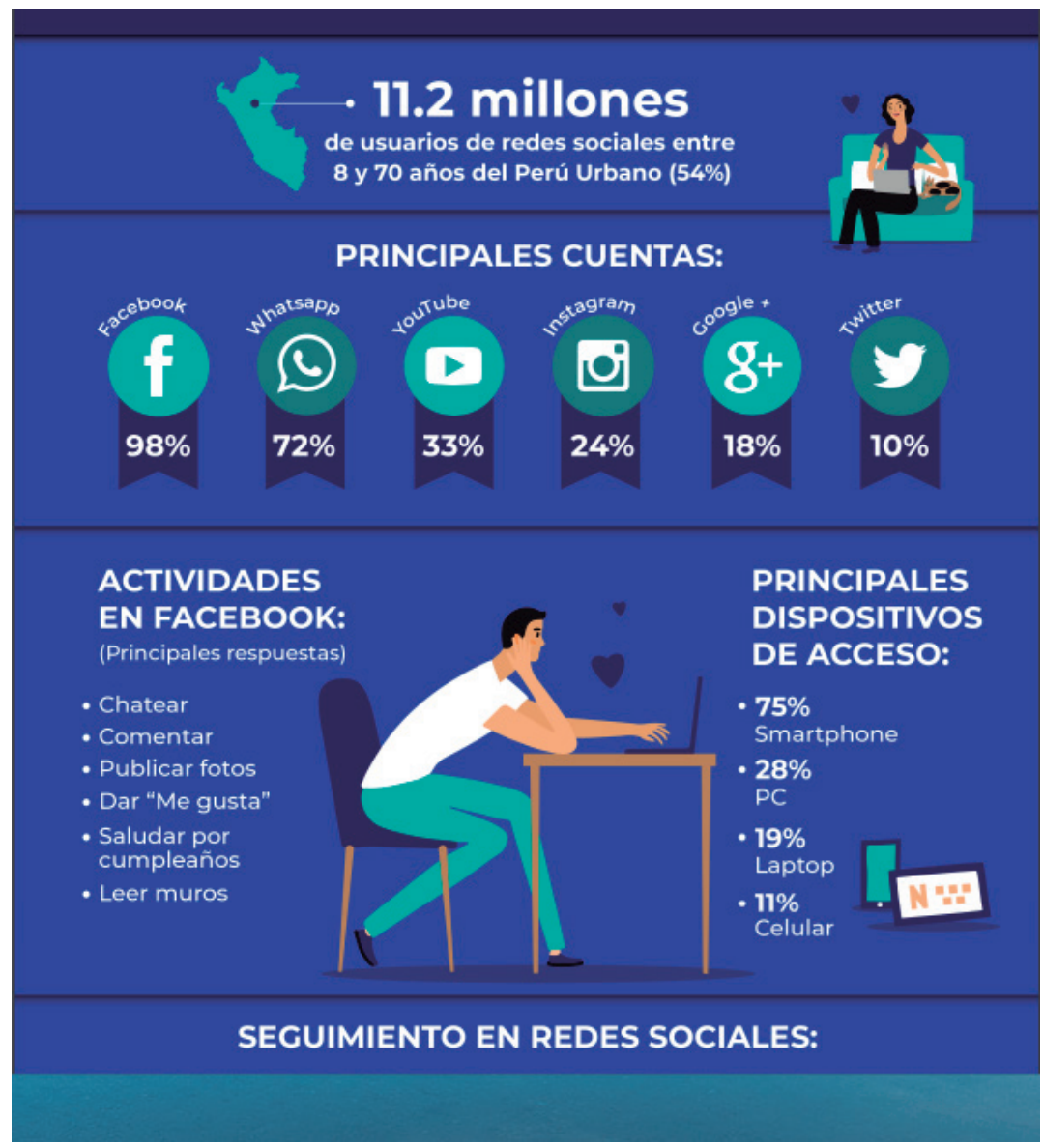

Figura $\mathbf{N}^{\circ} 1$ - Usuarios de Redes Sociales a nivel nacional

Fuente. Datos tomados de Ipsos Peru (2018, web)

Sin embargo, muchas instituciones públicas y privadas todavía no tienen la necesidad de incursionar en las redes sociales virtuales y esta resistencia se debe en algunos casos por un desconocimiento de los directivos y en otros por la falta de un administrador de redes sociales virtuales, ya que esto significaría un sueldo adicional por pagar.

Enel caso delas organizaciones gubernamentales, sehan visto obligadas ha incursionar en Facebook o Twitter para llegar a los ciudadanos de manera inmediata. Además han descubierto que es la forma correcta de trasparentar todas las actividades, ya que están en la obligación de comunicar a la ciudadanía en que se gastan los impuestos, tal como afirma Fernández y Alfaro (2017) donde menciona lo siguiente:

A través de las redes se puede establecer una comunicación horizontal, las personas asumen un rol más activo como agentes de cambio, vigilantes y protagonistas del progreso de su ciudad. Uno de los beneficios de la web 2.0 por parte de los organismos públicos es 
el fomento de la participación ciudadana, puesto que a través de ella existe la posibilidad de promover el desarrollo y solidaridad de la comunidad mediante actividades e iniciativa ciudadanas, incentivadas por las propias instituciones de gobierno (p.40).

En el caso de las organizaciones culturales las redes sociales virtuales se ha vuelto un elemento fundamental por el impacto visual que genera en los cibernautas, además de la cantidad de personas a las cuales puede llegar una publicación, asimismo permite construir una comunidad alrededor de los valores o actividades de una institución. Una de las más importantes es Facebook, ya que permite crear un "Fan page" o perfil virtual, asimismo, se puede subir fotos, videos, audios, textos, infografías y adicionalmente se hace trasmisiones en vivo con los usuarios, de esta manera se tiene un contacto directo con el público objetivo

Otra de las grandes ventajas que ofrece Facebook es la capacidad de establecer una conversación con los usuarios a través de la sala de chat, donde el seguidor tiene la posibilidad de escribirle directamente al responsable que maneja la cuenta de la institución, de esta forma le dice todo lo que piensa, esta información se vuelve importante ya que da pautas para mejorar.

Un aporte adicional que se tiene de la cuenta de Facebook es construir una base de datos de sus seguidores, gracias a la información que su obtiene se puede definir qué tipo de mensaje publicar, en que momento y medir el impacto de esa publicación Alexander Chiu (2012), especialista en marketing digital señala las ventajas que ofrece esta red social virtual:

La cualidad o tipo de información que nos ofrece Facebook es única. Podemos obtener variables de segmentación geográfica, (como el país, la ciudad y hasta el distrito o barrio de residencia) de segmentación sociodemográfica, como el género, las edades, el nivel de educación (en qué colegio o universidad estudias o estudiaste y de qué promoción eres), la orientación sexual, el lugar de trabajo, la profesión y el idioma. Y, además, de segmentación psicográfica flexible, pues brinda la posibilidad de poder definir palabras clave relacionadas con los gustos e intereses que queremos recopilar de las personas.

A esto debemos agregar que una de las herramientas persuasivas más efectivas son las que involucran la recomendación directa de tus familiares y amigos (como una publicidad 'boca a boca' virtual), que en el caso de Facebook se traduce en el texto de que a tus amigos 'les gusta' esa promoción, y que no hace más que elevar la confianza y el nivel de involucramiento $(2012$, web).

En conclusión, tener una cuenta en Facebook es una herramienta fundamental para cualquier organización pública o privada que quiera mantenerse vigente y crecer, ya que permite obtener información valiosa como las preferencias y costumbres de las personas, pero además es un elemento clave que gracias a sus diversos componentes, como audios, videos, se logra conseguir una comunidad virtual con valores y principios.

\section{Análisis de matriz de contenido de Facebook, interpretación y discusión de resultados}

Ana Sofia Pinedo y su equipo decidieron que era necesario hacer cambios en el área comunicacional para llegar a más personas. En medio de largas horas de conversación con todos los participantes, surge la idea de crear una cuenta en Blogspot.com y crear su propia blog institucional y llenarlo de información de Arena y Esteras. Al principio se llenó de texto y fotos de los primeros pasacalles, acompañado de una breve descripción, los resultados no se hicieron esperar ya que más personas se empezaron a interesar en las actividades que estaban realizando. 
Luego tomaron la decisión de ingresar al mundo de las rede sociales virtuales y el 28 de abril del 2010 sacan una cuenta en Facebook, donde ingresaron fotografías, audios y videos de las festivales que estaban realizando. Posteriormente ese mismo año, el 20 de agosto sacan una cuenta en Twitter.

Actualmente la cuenta tiene 9681 seguidores y es administrada por el área de comunicaciones, dirigida por Janeth Quispe Castillo, quien asume toda la responsabilidad, pero recibe la ayuda de los demás fundadores de la organización.

Para el presente análisis de contenido se ha revisado la información publicada en la cuenta de Facebook de la asociación, entre las fechas 02 de octubre al 26 de octubre del año 2018, para consolidar todos los resultados obtenidos, se ha elaborado el siguiente cuadro.

Tabla N¹. Matriz de Análisis de tipo de publicación en Facebook

\begin{tabular}{|c|c|}
\hline \multicolumn{2}{|c|}{ Revisión de publicaciones entre el 02 de octubre al 26 de octubre } \\
\hline Publicaciones en el día & $\begin{array}{l}\text { Del } 02 \text { al } 23 \text { de Octubre se realizó una publicación diaria. Solo los días 04, 15, } 24 \\
\text { y } 25 \text { se hicieron dos. El día } 20 \text { se hizo tres y el } 21 \text { se hicieron } 4 \text { publicaciones. }\end{array}$ \\
\hline Frecuencia de las publicaciones & $\begin{array}{l}\text { Todas las publicaciones se realizaron en el día del } 02 \text { al } 23 \text { de octubre se hicieron } \\
\text { en la mañanas. Solo las fechas } 04,15,24 \text { y } 25 \text { se realizaron una en la mañana } \\
\text { y otra en la tarde. El día } 20 \text { se hizo dos en la mañana y una la tarde y el } 21 \text { se } \\
\text { hicieron } 2 \text { en la mañana y } 2 \text { en la tarde. }\end{array}$ \\
\hline Material gráfico & $\begin{array}{l}\text { Del } 02 \text { al } 26 \text { de Octubre se han publicado fotografías en todas las publicaciones. } \\
\text { El día } 24 \text {, se publicó } 25 \text { fotos. El } 02 \text { se publicaron } 12 \text { fotos. El día } 25 \text { se han } \\
\text { publicado en una primera publicación una y en la segunda se han colocado } \\
\text { nueve imágenes. El } 04 \text { se han publicado cuatro y luego nueve fotografías. El } \\
16 \text { y } 20 \text { se subieron } 7 \text { fotos. El } 21 \text { de publicaron } 5 \text { imágenes, ese mismo día } \\
\text { se publicaron tres imágenes adicionales. El } 22 \text { solo se publicaron } 6 \text {. El } 15 \text { se } \\
\text { subieron } 4 \text { fotos. }\end{array}$ \\
\hline Material Audiovisual & Solo el día 21 de octubre se realizó una transmisión en vivo. \\
\hline $\begin{array}{l}\text { Me gusta, me encanta, me divierte, } \\
\text { me asombra, me entristece o me } \\
\text { enfada }\end{array}$ & $\begin{array}{l}\text { Desde } 02 \text { al } 26 \text { de Octubre se han encontrados me gustas en todas sus } \\
\text { publicaciones. Siendo las más altas el } 25 \text { de octubre } 92 \text { me gustas, el } 10 \text { de } \\
\text { octubre con } 57 \text {, el } 20 \text { con } 43 \text {, el } 02,04 \text { y el } 19 \text { con } 40 \text { me gustas. }\end{array}$ \\
\hline $\begin{array}{l}\text { Cantidad de veces que se comparte la } \\
\text { publicación }\end{array}$ & $\begin{array}{l}\text { En todas las fechas seleccionadas se han compartido las publicaciones. En las } \\
\text { fechas donde mayor cantidad de veces se compartido fue el } 19 \text { de octubre } \\
\text { donde se compartió } 27 \text { veces, el } 10 \text { se compartió } 21 \text { veces, el } 09 \text { se compartió } 17 \text {, } \\
\text { el } 22 \text { se compartió } 11 .\end{array}$ \\
\hline $\begin{array}{l}\text { Cantidad de comentarios por } \\
\text { publicaciones }\end{array}$ & $\begin{array}{l}\text { Durante todas las fechas seleccionadas se han realizado comentarios. El } 04,09 \text {, } \\
22 \text { y el } 15 \text { solo uno. El 10, 20, } 23 \text { y } 25 \text { dos comentarios y el } 21 \text { se comentó } 8 \text { veces. }\end{array}$ \\
\hline
\end{tabular}

Fuente: Elaboración propia.

Adicionalmente se ha hecho una revisión de los contenidos publicados de manera diaria, durante las fechas del 02 al 26 de octubre del año 2018, para tener resultados más precisos; asimismo, se aplicó la siguiente categorización (ver tabla $\mathrm{N}^{\circ} 2$ ).

Tabla N². Matriz de Análisis de tipo de publicación en Facebook

\begin{tabular}{ll}
\hline \multicolumn{1}{c}{ Tipo de publicación } \\
\hline Informativo \\
Promocional \\
Contenido Interesante \\
\hline
\end{tabular}

Fuente: Elaboración propia.

Este análisis se fundamenta en el trabajo realizado por Vivero, en su tesis de Licenciatura en Comunicaciones, sobre el análisis de la imagen en Facebook de la Reserva Ecológica Santa Rita, para la Facultad de Comunicación, Lingüística Y Literatura, de la Pontificia Universidad Católica del Ecuador. Donde señala que: 
Tipo de publicación: En esta categoría se define la naturaleza de la información publicada

- Informativa: Se denomina a una publicación que comunica los servicios que la RESR ofrece, el día, la fecha y la hora de la competencia de la que es parte.

- Promocional: Es una publicación que informa promociones o descuentos obtenidos por realizar un llamado a la acción: dar un "me gusta", comentar, compartir, etc.

- Contenido interesante: Es una publicación que contiene información que puede ser de interés para el usuario, no precisamente sobre la RESR, pero sí relacionada con los temas que giran alrededor de la misma: campismo, deportes de aventura, pesca o andinismo, entre otros (Vivero, 2016, pp. 57-58).

Una demostración de lo mencionado se puede apreciar revisando la captura de la imagen de la cuenta de Facebook, del 02 de Octubre, con título I Congreso de Políticas Públicas para la Cultura Viva Comunitaria.

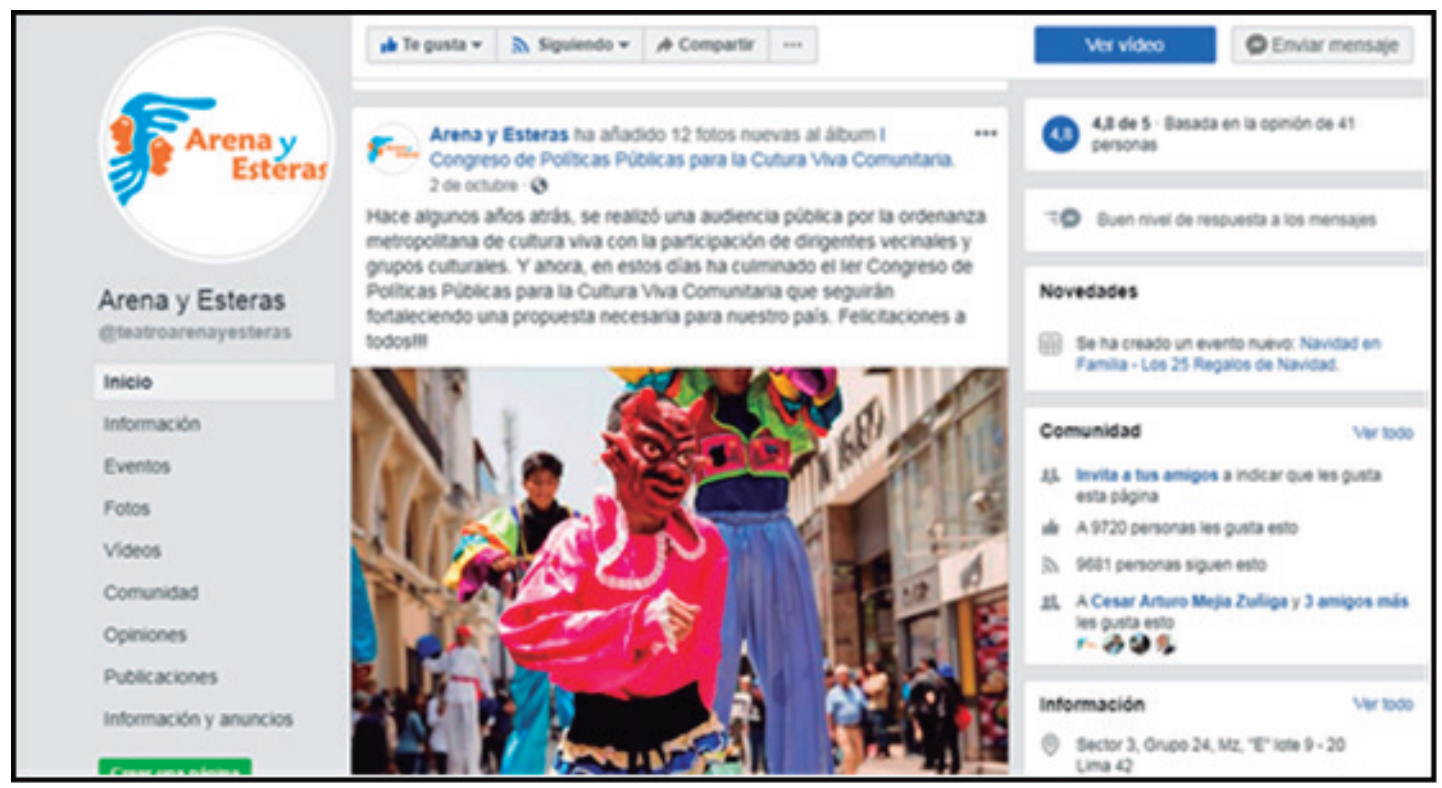

Figura $\mathbf{N}^{\circ} \mathbf{2}$ - Cuenta de Facebook de Arena y Esteras

Otra fechas que tuvo un impacto fuerte y generó mayor cantidad de visualización y seguidores fue el 21 de Octubre, con el título Transmitido en directo, estos resultados se pueden apreciar revisando la captura de la imagen de la cuenta de Facebook.

Tabla N³. Matriz de Análisis de tipo de publicación en Facebook

\begin{tabular}{ll}
\hline & Tipo de publicación \\
\hline Informativo & 1 \\
Promocional & \\
Contenido Interesante & \\
\hline
\end{tabular}

Fuente: Elaboración propia. 


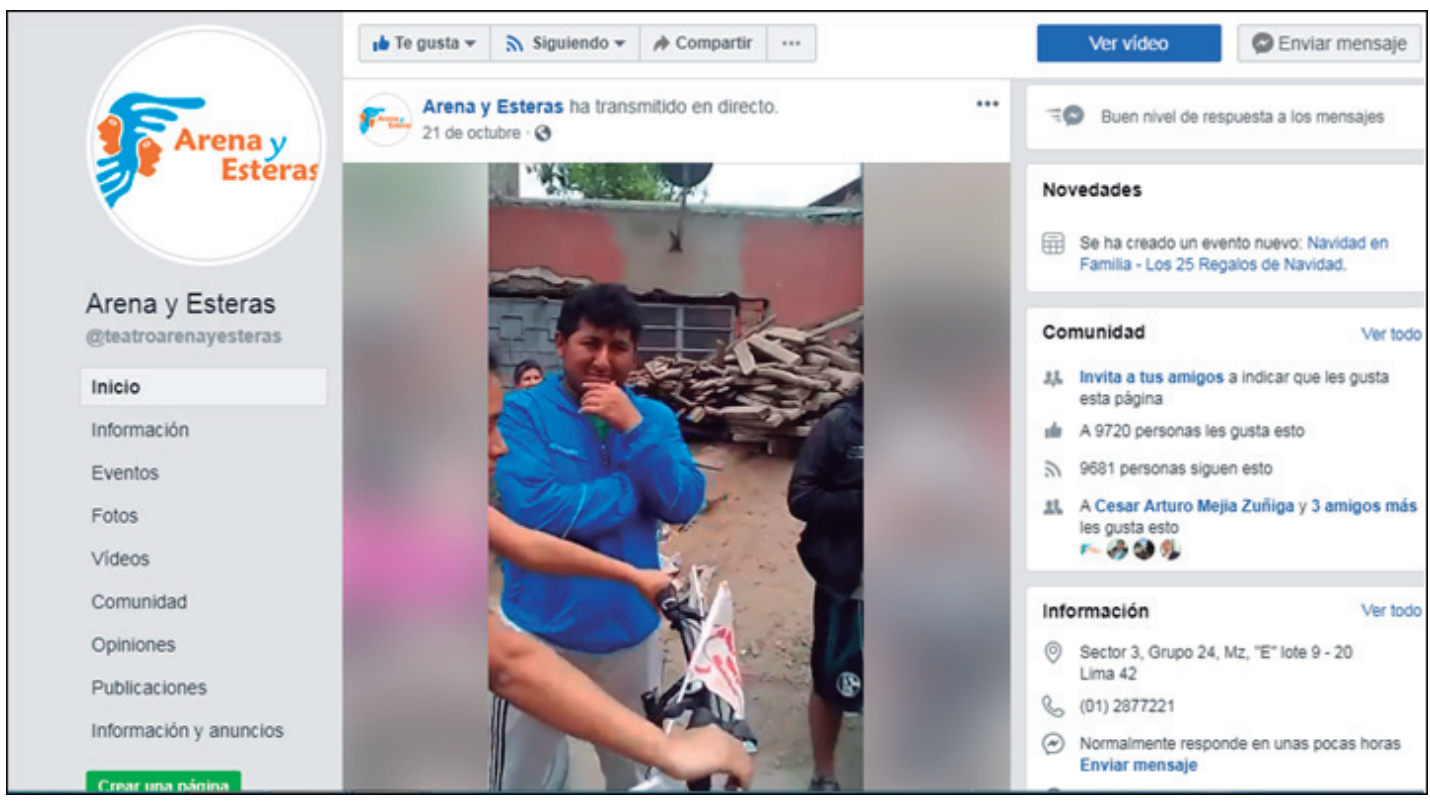

Figura $\mathbf{N}^{\circ} \mathbf{3}$ - Cuenta de Facebook de Arena y Esteras

\section{Conclusiones}

La Asociación Cultural Arena y Esteras es una organización que tiene como objetivo principal el desarrollo del ser humano a través del arte. Inculcando a sus miembros los valores de respeto, solidaridad y compromiso con su comunidad. A pesar de haber surgido en la década de los noventa, donde los actos terroristas de Sendero Luminoso eran constantes, Ana Sofia Pinedo y todo su equipo de trabajo no se acobardaron y tomaron la decisión, que cambio por completo el futuro de sus vidas, de realizar pasacalles, festivales, obra de teatro con el fin de darle una sonrisa a una población golpeada por la pobreza y la injusticia.

En sus años de inicio recibieron varios premios ya que participaron en diversos concursos nacionales de teatro. Además de haber ganado diversos premios internacionales. Gracias a su trabajo compraron un terreno y construyeron un local donde realizan talleres y presentaciones para los habitantes de Villa El Salvador.

A nivel organizacional uno de los aspectos más importante a destacar es el relacionado al trabajo colaborativo entre todos sus integrantes, quienes siempre buscan el bienestar de los demás por encima de las ambiciones personales, esto demuestra el sentido de unidad y bienestar común que todavía está presente en las nuevas generaciones.

En el punto relacionado a la cultura organizacional se identifica tres valores esenciales: el colectivismo, el cual sostiene que solo la acción grupal y mancomunada de todos sus integrantes va a permitir superar cualquier barrera; la territorialidad, concepto que establece que el desarrollo de la asociación va permitir el crecimiento de Villa El Salvador y el normativismo, el cual significa que todos sus integrantes deben seguir las reglas que establece la asociación, siendo una de las más importantes promover el arte en la población más vulnerable como son los niños.

La importancia de inculcar en los niños, adolescentes y jóvenes los valores como respeto, solidaridad y compromiso con tu comunidad van a permitir la construcción de una sociedad sin discriminación, consiguiendo ciudadanos responsables. De esta forma, se enseña a los niños desde pequeños a realizar trabajos gratuitos con el fin de ayudar y darles alegrías a toda su comunidad.

Los valores como solidaridad, honestidad y respeto han permitido que la organización se fortalezca con los años. Además, se ha podido comprobar como el concepto 
cooperativista se aplica esta en la remuneración de los miembros de la asociación, ya que todos reciben un mismo sueldo, no existe preferencia, ni distinción.

A lo largo de estos 27 años de funcionamiento, la socialización de la cultura organizacional se ha conseguido gracias a la identificación de sus integrantes con su comunidad y a las constantes actividades con el fin de ayudar a los niños, esto ha permitido la unificación de los diversos miembros de Arena y Esteras.

Un punto que ha generado un quiebre en el desarrollo de la asociación son las redes sociales virtuales, especialmente la cuenta de Facebook de Arena y Esteras, el cual le ha permitido aumentar la capacidad de difusión y divulgación de sus actividades Además de conseguir una comunidad virtual que sigue cada festival, pasacalle y obra de teatro que realizan. Por otro lado, le ha permitido publicar fotografías y realizar transmisiones en vivo o Facebook Live consiguiendo de esta forma más seguidores.

En la revisión de toda la información publicada en la cuenta de Facebook se puede concluir que es útil para la asociación, ya que cada uno de los post ha generado un comentario entre los usuarios, además han logrado aumentar los seguidores y consolidado a su comunidad virtual. Con respecto a la calidad de contenido se puede señalar que básicamente lo utilizan como un medio de promoción de las actividades.

\section{Referencias Bibliográficas}

Arnao, J. \& Surpachin, M. (2016). Uso y abuso de las redes sociales digitales en los adolescentes y jóvenes. Lima: Centro de Información y Educación para la Prevención del Abuso de Drogas.

Arbaiza, L. (2010). Comportamiento Organizacional: bases y fundamentos. Buenos Aires: Cengage Learning.

Arenas y Esteras (2011a) Carpeta Institucional-Arena y Esteras. Lima.

Arena y Esteras (2011b) Casa Cultural Comunitaria Arena y Esteras. [brief]. Lima.

Arena y Esteras (2016). ¡Por el derecho a la sonrisa!, Circo Social desde Villa El Salvador: La experiencia de Arena y Esteras. Recuperado de http://www.infoartes.pe/wpcontent/uploads/2017/11/Por_Derecho_Sonrisa_2.pdf?fbclid=IwAR1bh958uB5R66gNMWRkAa7VdwbXQGR3t2jiHWIjYB4SI-F8XesHDIBymY

Biondi, J.; Miró Quesada, S. \& Zapata, E. (2010). Derribando muros. Periodismo 3.0: oferta y demanda de la comunicación en el Perú de hoy. Lima: Empresa Editora El Comercio S.A.

Bradley, A. \& McDonald, M. (2016). La organización social. Lima: Punto y Coma Editores.

Bourdieu, P. \& Wacquant, L. (2005). Una invitación a la sociología reflexiva. Buenos Aires: Siglo XXI Editores Argentina.

Bustamante, E. (2008). Redes Sociales y Comunidades Virtuales en Internet. México D.F.: Alfaomega.

Cánepa, M. \& Ruiz, R. (2003). Valores, afectos y motivaciones en grupos juveniles. Lima: Centro de Estudios y Publicaciones.

Castells, M. (2012). "El poder tiene miedo de Internet". Extraído el 26/III/2016 desde http://www.elpais.com/articulo/reportajes/poder/tiene/miedo/Internet/ elpepusocdmg/20080106elpdmgrep_5/Tes.

Castells, M. (2012). Comunicación y poder. México D.F.: Siglo XXI.

Castells, M. (2011). La Sociedad Red: una visión global. Madrid: Alianza Editorial.

Castells, M. (2001). La Galaxia Internet. Barcelona: Areté.

Contreras, F.; Gomero, F.; Herrera, D. \& Quijano, L. (2015). Efecto del Uso de Redes Sociales Virtuales en Mujeres Empresarias del Perú [Tesis de magíster en administración estratégica de empresas]. Lima: Escuela de Postgrado, Pontificia Universidad Católica del Perú. 
Chiu, A. (2012 febrero 20). "El valor publicitario de Facebook". En Blog Anuncias luego existes. Recuperado de http://blogs.gestion.pe/anunciasluegoexistes/2012/02/el-valorpublicitario-de-faceb.html.

Escudero R. (2017). Plan estratégico de comunicación para el mejoramiento del fundraising y posicionamiento de la asociación cultural arena y esteras de villa el salvador (20142015) [Tesis de magister publicada]. Lima: Escuela de Postgradeo, Pontificia Universidad Católica del Perú.

Fernández, N. \& Alfaro, Y. (2017). Las redes sociales en las organizaciones. Trujillo: Imprenta Editora Gráfica Real S.A.C.

Gestion, (2019). Social Media: Perú es el primer país de la región con mayor porcentaje de alcance de redes sociales. Recuperado de https://gestion.pe/tecnologia/social-mediaperu-primer-pais-region-mayor-porcentaje-alcance-redes-sociales-258321-noticia/

Ipsos Perú (2016). Perfil del usuario de redes sociales. Lima: Ipsos Perú.

Ipsos Perú (2018). Usuario de rede sociales a nivel nacional 2018. Recuperado de https://www. ipsos.com/sites/default/files/ct/publication/documents/2018-09/perfil_del_usuario_ de_redes_sociales.pdf

Jove, H. \& Neira, I. (2017). Sociología de las organizaciones e instituciones. Puno. Emer Impresiones.

Lay, J. (2012). “20 años de alegría rebelde, implicancias de la cultura organizacional en la sostenibilidad de una organización de la sociedad civil una aproximación desde el caso de la Asociación Cultural Arena y Esteras. 2008-2012". [Tesis de Licenciatura en Gestión Social no publicada]. Lima: Facultad de Gestión y Alta Dirección, Pontificia Universidad Católica del Perú.

Manrique, N. (2016). Una alucinación consensual redes sociales, cultura y socialización en internet: Lima: Fondo Editorial de la Pontificia Universidad Católica del Perú.

Manrique, N. (2015). El tiempo del miedo: la violencia política en el Perú 1980 -1996. Lima: Fondo Editorial del Congreso del Perú.

Mejia, A., entrevista personal. Lima, 02 de Enero del 2018.

Panfichi, A. \& Alvarado M. (2009). Desconfianza y Control: Ong y Politica en el Perú. Recuperado de http://blog.pucp.edu.pe/blog/wp-content/uploads/sites/38/2010/08/Texto-CompletoONG-PERU.pdf

Portocarrero, F.; Sanborn, C.; Cueva, H. y Millán, A. (2002). Más allá del individualismo: el tercer sector en el Perú. Lima: Centro de investigación de la Universidad del pacífico.

Rodríguez, D. (2001). Gestión organizacional: Elementos para su estudio. Santiago de Chile: Ediciones Universidad Católica de Chile

Simmel, G. (2014). Sociología: estudios sobre las formas de socialización. México D.F.: Fondo de Cultura Económica.

Teresa, M; Marcone, S y Anguis, R. (2012). Jóvenes e internet la cultura de las TIC. Lima: Centro de Estudios y Publicaciones.

Vargas Llosa, M. (2011, Julio 31). “Más información, menos conocimiento”. La República, pp.18-19.

Vivero, M. (2016). Análisis de la imagen en Facebook de la Reserva Ecológica Santa Rita entre los deportistas de aventura (tesis de licenciatura). Pontificia Universidad Católica Del Ecuador, Quito, Ecuador. Recuperado de http://repositorio.puce.edu.ec/bitstream/ handle/22000/12770/FINAL\%20REVISION\%20MCC\%20CORRECCIONES\%20 HECHAS\%2014nov\%20\%284\%29.pdf?sequence=1\&isAllowed=y

Vizcarra, E. (16 de Febrero del 2018). "Perú en Redes Sociales 2018 (Parte I)”. La República. Recuperado de https://larepublica.pe/sociedad/1198456-peru-en-redes-sociales-2018parte-i 